\title{
Assessing impacts of Common Agricultural Policy changes on regional land use patterns with a decision support system An application in Southern Portugal
}

\author{
P.J. Borges ${ }^{\text {a }}$, R. Fragoso ${ }^{\text {b }}$, J. Garcia-Gonzalo ${ }^{\text {a,* }}$, J.G. Borges ${ }^{\text {a }}$, S. Marques ${ }^{\text {a }}$, M.R. Lucas ${ }^{\text {b }}$ \\ a Centro de Estudos Florestais, Instituto Superior de Agronomia, Technical University of Lisbon, Portugal \\ ${ }^{\mathrm{b}}$ University of Évora/Management Department/ICAM, Évora, Portugal
}

\section{A R T I C L E I N F O}

\section{Article history:}

Received 8 April 2009

Received in revised form 31 August 2009

Accepted 3 September 2009

\section{Keywords:}

Decision support system

Mathematical programming

Land use pattern

Agricultural policy

Simulation

\begin{abstract}
A B S T R A C T
This paper discusses research aiming at assessing Common Agricultural Policy impacts on agriculture and forestry. For this purpose an approach is developed that includes a linear programming model to estimate the Positive Mathematical Programming production cost function coefficients of current agriculturalforestry activities. It further includes a heuristic - simulated annealing - to generate solutions for each policy scenario. This model base approach is integrated within a decision support system (DSS) for testing purposes. The DSS further encompasses a relational database that stores agricultural-forestry technical and economic data and a geographic information system that stores topological data of regional farm-type land units. The DSS Graphical User Interface provides tabular and geographical reporting capabilities. Results are discussed for an application to the Alentejo region in Southern Portugal. Results demonstrate the usefulness and relevance of the proposed approach to assess the impact of changes in prices and in agricultural policy on land use patterns and on forestry.
\end{abstract}

(c) 2009 Elsevier B.V. All rights reserved.

\section{Introduction}

Land use is a key human activity that drives socio-economic development in rural regions. The reforms of the European Common Agricultural Policy (CAP) have shaped European agriculture and the spatial distribution of agriculture, forestry and livestock management activities. CAP motivations included land use efficiency and socioeconomic development (van Delden et al., 2008). The current CAP emphasises direct payments to farmers in order to support farmer income, food safety and quality, and environmentally sustainable production (Bach et al., 2008).

Recently, the European Council of Ministers discussed the longterm EU budget for the period 2006-2013. Some member states proposed to reduce or abolish the CAP. These proposals were unsuccessful and yet in 2012 a new budget will be discussed that may have a substantial impact on European agriculture. Changes in the agricultural policies will likely have a direct effect on land use in agricultural rural areas of the EU (Bakker et al., 2008). Moreover, changes in prices and/or in demand also impact land use patterns in these areas. Thus, tools are required that may help anticipate the impacts of changes in policies and/or prices on land use patterns.

\footnotetext{
* Corresponding author. Centro de Estudos Florestais, Instituto Superior de Agronomia, Technical University of Lisbon, Tapada da Ajuda, 1349-017 Lisboa, Portugal. Tel.: +351 213653366; fax: +351213653338.

E-mail address: Jordigarcia@isa.utl.pt (J. Garcia-Gonzalo).
}

Mathematical programming (MP) models have been frequently used in agricultural economics. In general, these MP models aim to assess economic, technical and institutional scenarios associated with changes in relative prices, in technologies and in the availability of inputs (McCarl and Spreen, 1980). In order to further assess agricultural and rural development policies, Howitt (1995) proposed the Positive Mathematical Programming (PMP) approach. PMP has been used extensively to analyse economic, social and environmental problems in the framework of the Common Agricultural Policy (Gohn and Chantreuil, 1999; Cypris, 2000; Baskaqui et al., 2001; Graindorge et al., 2001; Helming et al., 2001; Fragoso et al., 2008).

Decision support systems (DSS) are designed to assist in identifying patterns, problems, opportunities, and eventually in making decisions (e.g. Zahedi et al., 2008). Moreover, DSS provide an interesting framework to integrate database management systems with analytical and operational research models, graphic and tabular reporting capabilities to assist in natural resources management and policy analysis (e.g. Borges et al., 2003; Reynolds et al., 2005, 2008).

This paper demonstrates the use of a model base approach to anticipate the impacts of changes in CAP and/or in prices on land use in rural areas (including forest land). The model based is integrated within a DSS with a modular structure. The DSS further include an information module that stores spatial and aspatial data to characterize farm types. The model base approach encompasses three components: i) a scenario generator, used to create different policy and/or price scenarios, ii) mathematic programming models to 
represent scenarios and to generate economic information as proposed by the PMP approach and iii) a meta-heuristic - simulated annealing - for model solving e.g. for estimating land use changes in each farm type. The third DSS module is a Graphical User Interface. It enables checking and editing scenarios. It further provide functionalities for model building, model solving and for reporting results.

Results are reported for an application to the Alentejo region in Southern Portugal encompassing 31 farm types extending over $2 \times 10^{6}$ ha. They suggest that the proposed approach is capable of efficiently and effectively assessing the impact of changes in prices and in agricultural policy on land use patterns and on forestry.

\section{Material and methods}

\subsection{Study area}

Alentejo is a region located in Southern Portugal that extends over one third of the country's area. Agriculture and agro-forestry are the most important economic activities in its rural areas. The region has been facing serious social and economic problems, the most visible being the decrease and ageing of its population. The agricultural sector in the Alentejo is characterized by a small number of large farms. According with agricultural statistical census of 1999 (INE, 1999), the regional farm average size was above 40 ha, which is much higher than the average value in Portugal (9 ha).

A great part of the region (over than 1 million ha) is covered by a Mediterranean agro-forest in which Quercus ilex spp. rotundifolia and Quercus suber dominate. This is an agro-forestry system in which agricultural and forest activities complement each other. In Portugal, this agro-forestry system is named "Montado". It produces cork, firewood and fodder for livestock in grazing extensive agricultural systems with cereals and other crops. Agro-forestry is understood here as a land use system where woody perennials, agricultural crops and/or animals occupy the same land management unit, in some form of spatial arrangement or of temporal sequence and where there are both ecological and economic interactions between the system's components (Somarriba, 1992). Agro-forestry can be generally classified into silvoarable (tree-crop) and silvopastoral (tree-livestock) systems. Often, the farm management strategy within "Montado" encompasses a combination of these systems. In Southern Portugal the "Montado"'s cork and holm oak stands have varying densities and crops/fallow/ pastures are managed in rotation under the oak canopy (Pinto-Correia and Mascarenhas, 1999).

The Alentejo Region in Southern Portugal is far from homogeneous. Agro-forest-ecological heterogeneity provides the framework for economic activities, particularly for agro-forestry activities. Thus agro-forestry land was classified into 31 farm types (Fig. 1) based on ecological characteristics and on current land use patterns (Borges et al., 2008a, b) to provide the spatial building blocks for testing the proposed approach. Current land uses in the Alentejo Region include cereals, horticulture, fruit culture trees, vineyards, olive trees, permanent pastures, forage, set-aside, fallow and forest. In this research, the forest land use is defined as forest area with no agriculture activity under canopy cover. Land uses within the "Montado" agro-forestry system include livestock, common wheat, durum wheat, sunflower, forage, fallow, pastures and set-aside.

\subsection{Mathematical model}

PMP is a method to calibrate mathematical programming models according to observed behaviours during a reference period. For that purpose it uses the information provided by the dual variables of the calibration constraints (Howitt, 1995; Paris and Howitt, 1998). In this study, a PMP supply agricultural model was developed to simulate farmer's response to changes in agricultural policies and product prices. This model was included in the model base of the proposed DSS in order to evaluate the Common Agricultural Policy impact on farm types in the region.
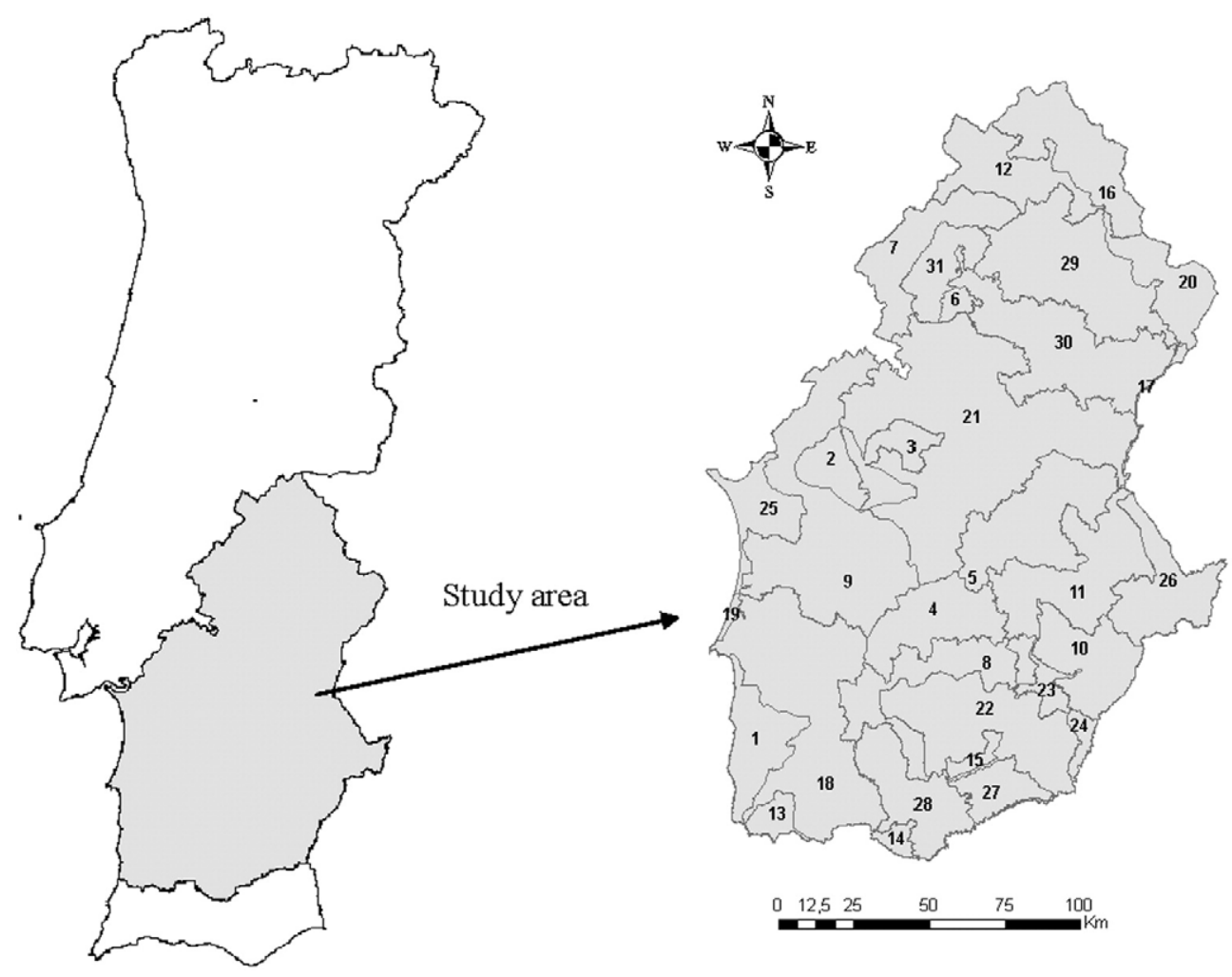

Fig. 1. Agro-forestry farm-type land units within the Alentejo region (Portugal). 
The PMP approach encompassed two steps. In step I, calibration constraints were used so that a gross margin maximization LP model did comply with current agriculture and livestock activity levels:

$\operatorname{MaxZ}=\sum_{i} \sum_{j} \sum_{a} g m_{i, j, a} X_{i, j, a}+\sum_{i} \sum_{p} g m_{i, p} Y_{i, p}$

Subject to:

$\sum_{p} c n_{i, f} Y_{i, p} \leq \sum_{a} X_{i, j, a} \forall i, a$ and $f \in j$

$\sum_{i} \sum_{j} \sum_{a} X_{i, j, a} \leq S A_{i} \forall i$

$X_{i, j . a} \leq X_{i, j, a}^{0}(1+\varepsilon) \forall i, j, a$

$Y_{i, p} \leq Y_{i, p}^{0}(1+\varepsilon) \forall i, p$

Eq. (1) is the objective function. It maximizes the total gross margin in Euros $(Z)$ : the sum of the agro-forestry and livestock activities gross margins in Alentejo. These are a function of unit gross margins ( $\mathrm{gm}$ ) and of both number of hectares $(X)$ of agro-forestry activities $(j)$ that are supported by subsidies $(a)$ and number of units $(Y)$ of livestock activities $(p)$, in each regional farm type $(i)$

Agro-forestry activities include cereals (soft wheat, durum wheat, maize, and rice), oil seeds (sunflower), horticulture, fruit culture (melon and tomato), fruit trees, vineyards, olive tree, permanent pastures, forage, set-aside, fallow and forestry. Livestock activities include beef cattle, sheep and extensive swine productions. Typically these agro-forestry activities are conducted under tree cover. Permanent pastures and forages, mostly under cork and holm oak cover, are intermediate activities $\left(X_{i, f, a}\right)$ that provide input for livestock

Eq. (2) defines the balance between forage areas $\left(X_{i, f a}\right)$ and the number of livestock $\left(Y_{i, p}\right)$. The parameter $\mathrm{cn}_{i, f}$ corresponds to the livestock stocking rate of activity $f$ in regional farm type $i$. Eq. (3) is an area constraint that ensures that the number of ha assigned to each land use does not exceed the area available in each regional farm type $(i)$ $\left(S A_{i}\right)$. Eqs. (4) and (5) are the calibration constraints. In these equations, decision variables $X$ and $Y$ are bounded by parameters $X_{i, j, a}^{0}$ and $Y_{i, p}^{0}$ that correspond to current levels of agro-forestry and livestock activities, respectively. The LP model solution will thus replicate the current land use pattern. Further, the shadow prices of calibration constraints will reflect the implicit marginal cost of each activity.

In step II, the information provided by the dual variables of Eqs. (4) and (5) was used to formulate a non-linear model without boundary constraints:

$$
\begin{aligned}
\operatorname{MaxZ}= & \sum_{i} \sum_{j} \sum_{a} g m_{i, j, a} X_{i, j, a}-\sum_{i} \sum_{j} \sum_{a}\left(a_{i, j, a} X_{i, j, a}+\frac{1}{2} \beta_{i, j, a} X_{i, j, a}^{2}\right) \\
& +\sum_{i} \sum_{p} g m_{i, p} Y_{i, p}-\sum_{i} \sum_{p}\left(a_{i, p} Y_{i, p}+\frac{1}{2} \beta_{i, p} Y_{i, p}^{2}\right)
\end{aligned}
$$

where, $\alpha$ and $\beta$ are the calibration coefficients of the production cost function. They were calculated by Eqs. (7) and (8) for the agroforestry $(j)$ and livestock activities $(p)$, respectively:

$$
\begin{aligned}
& \alpha_{i, j, a}=\rho_{i, j, a}-\beta_{i, j, a} X_{i, j, a}^{0} \text { and } \beta_{i, j, a}=\varepsilon_{j}^{-1} \cdot \frac{p_{j}^{0}}{X_{i, j, a}^{0}} \\
& \alpha_{i, p}=\rho_{i, p}-\beta_{i, p} Y_{i, p}^{0} \text { and } \beta_{i, p}=\varepsilon_{p}^{-1} \cdot \frac{p_{p}^{0}}{Y_{i, p}^{0}} .
\end{aligned}
$$

These calibration coefficients represent the marginal production costs. Their values are a function of shadow prices $\rho_{i, p, a}$ and $\rho_{i, p}$ from Eqs. (4) and (5), of price elasticity of supply $\varepsilon_{j}$ and $\varepsilon_{p}$, of relative prices $p^{0}{ }_{j}$ and $p^{0}{ }_{p}$ and of current levels of agro-forestry and livestock activities $X_{i, j, a}^{0}$ and $Y_{i, p}^{0}$.

\subsection{Simulating annealing adapted for assessing policy impacts}

Heuristics are techniques that may circumvent computational constraints to using mathematical programming approaches (Borges et al., 2002). The proposed model base includes a simulated annealing (SA) algorithm to approximate solutions to the non-linear model in Eq. (6).

SA involves a sequence of iterations each consisting of randomly changing the current solution to find a new solution in the neighbourhood of the current solution (Pham and Karaboga, 2000). In order to avoid premature convergence to a local optimum, an inferior solution may be accepted. Yet, the frequency of these moves decreases with the iteration number according to the value of a control parameter (temperature) (Reeves, 1993). The probability of accepting inferior solutions increases with temperature, and it decreases with the magnitude of the inferior solution. Key to successful algorithm implementation is the choice regarding the solution data structure, the fitness evaluation function and the cooling schedule (Pham and Karaboga, 2000). In general, the latter involves the specification of the initial temperature parameter, of the rate at which the temperature is reduced and of the number of iterations at each temperature. The convergence process may be stopped when the temperature reaches a minimum value. Rather than setting the number of iterations at each temperature, the implementation of SA in the proposed DSS uses a parameter (Mov) that limits the number of moves (number of variables that are changed in each iteration).

The system Graphical User Interface (GUI) asks the user to input SA parameters such as initial temperature, minimum temperature, temperature reduction factor, maximum number of iterations, number of moves and maximum number of iterations within the current solution (Fig. 2). Then a number of steps are followed:

1. The algorithm produces an initial solution by assigning a random number of hectares $(X)$ to each agro-forestry activity $(j)$ with support by subsidy $(a)$ and a random number of units $(Y)$ to each livestock activity $(p)$, in each regional farm type $(i)$ (Eq. (1)). The algorithm proceeds by computing this solution value (energy calculation)

2. In each iteration, a specified number of activities are selected from all the possible agro-forestry and livestock activities $\left(X_{i, j, a}\right.$ and/or $Y_{i p}$ ). This number corresponds to an algorithm parameter (i.e. number of moves). A new solution is generated by assigning a new random value (i.e. number of hectares or units) to the selected activities. The new solution is evaluated and compared to the previous one to see whether there is an improvement or not.

3. If there is an improvement then the proposed modification is accepted and the new solution becomes the current solution. Further, the temperature is lowered, the iteration number within the current solution is set to 0 and the procedure jumps to step 9 .

4. If there is no improvement then whether an inferior solution is accepted or not depends on the outcome of a comparison between a random number and the value of an exponential acceptance function $(Z=\exp ((z 1-z 2) /$ temp $)$;

5. If the inferior solution is accepted, the new solution becomes the current solution. Further, the temperature is lowered, the iteration number within the current solution is set to 0 and the procedure jumps to step 9.

6. If the inferior solution is not accepted then the iteration number within the current solution is increased. If this number does not reach the maximum number of iterations within the current solution the procedure jumps to step 9 else the number of moves (number of variables that would be changed) allowed is reduced; 


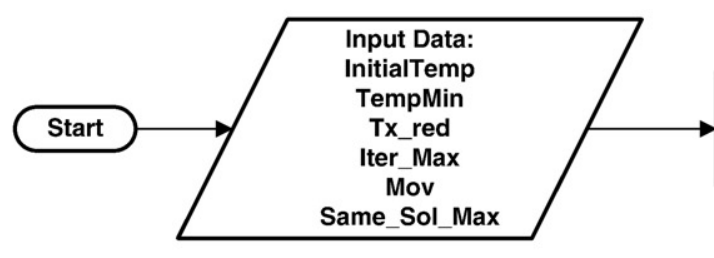

Generate Initial Random solution

Present Solution $=$ Gen. Random Solution

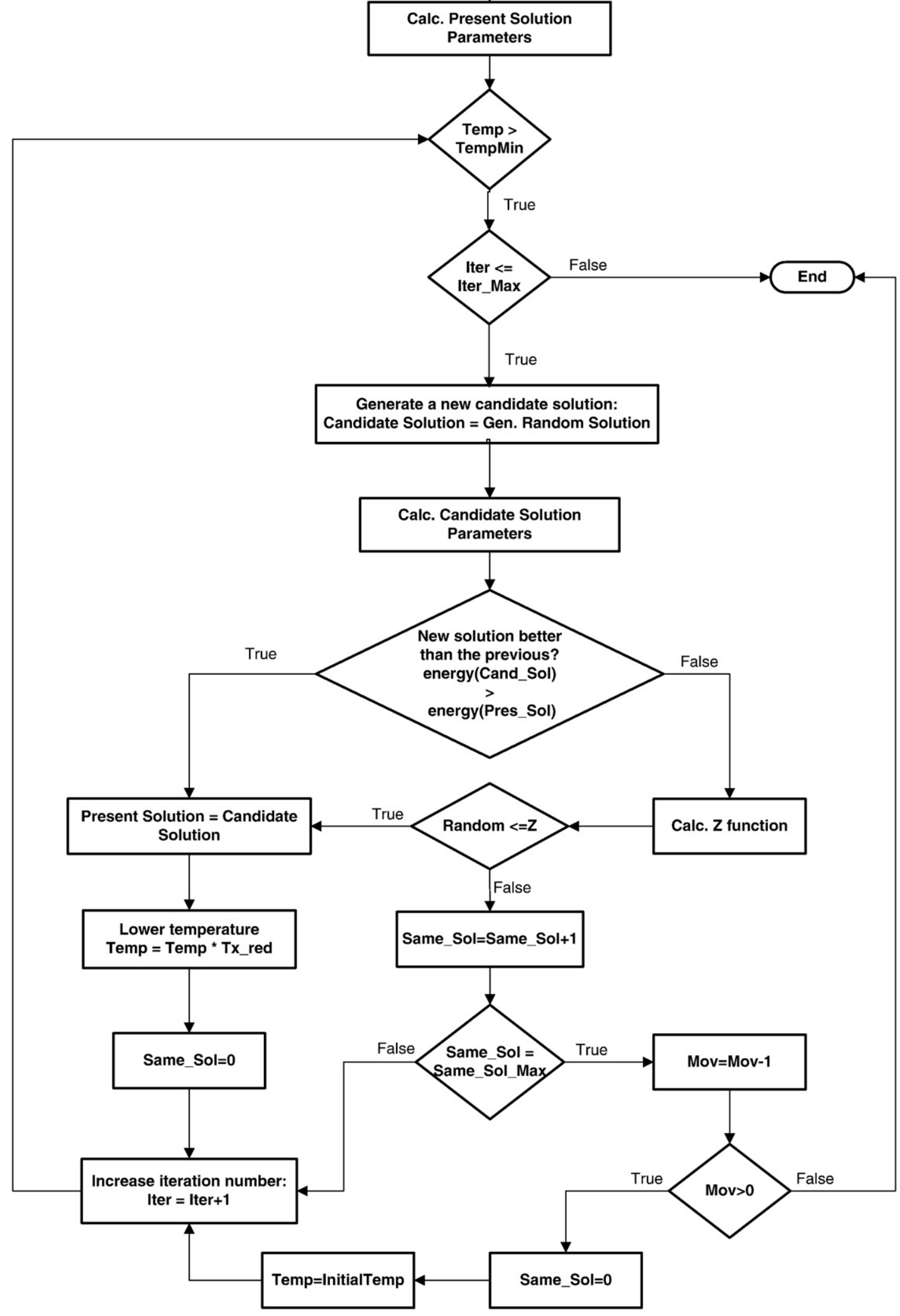




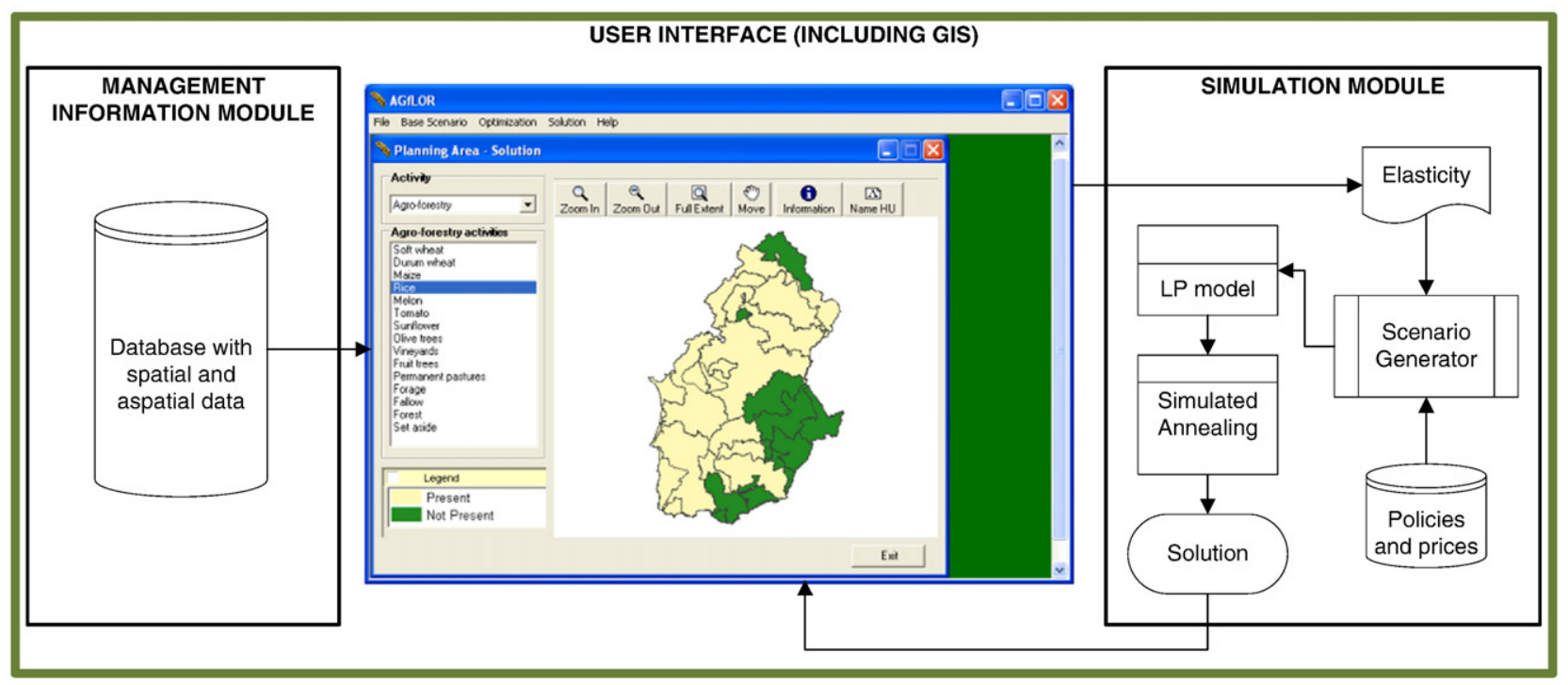

Fig. 3. Structure of AGfLOR showing the different modules within the DSS.

7. If the number of moves allowed is 0 the process is finished and the final solution is reported.

8. If the number of moves is higher than 0 then the iteration number within the same solution is set to 0 , the temperature is set to the initial value and the process continues to step 9 .

9. The number of iterations is increased and if it has not reached the maximum a new solution is proposed (step 2), otherwise the process is finished and the final solution is reported.

The implementation of SA in the proposed DSS encompassed the following parameters: maximum number of iterations $=250,000$, initial temperature $=100$, final temperature $=0$, maximum number of iterations within the current solution $=500$ (triggering reduction in number of changes allowed), temperature reduction factor $=0.999$. The number of simultaneous changes allowed (i.e. number of moves) at the beginning of the optimisation process is 6 and decreases during the search process.

\subsection{DSS overview}

The DSS that integrates the proposed model base (AGfLOR) encompasses two further modules: i) information module, and ii) a graphical user interface incorporating a GIS used as a means of visualising input data and results (Fig. 3). The program was developed in VB.NET 2003 under Windows XP. Yet the compiled program runs in any Win32 platform (Windows 95/98, Me, 2000, XP and Vista). Visual Basic was chosen due to its rapid prototyping capabilities, robust interface design, and extensive graphics capabilities.

The user has access to the information system where the data of the study area is stored. The information system stores farm-type agroforestry technical and economic data. The geographic information system stores topological data to allow spatial recognition and analysis of land units within the study area. The simulation module includes the scenario generator and the mathematical models as well as the metaheuristic (simulated annealing) used for solving the mathematical models. The scenario generator automates the processes for defining or selecting product prices and supply elasticity, and subsidies for each agro-forestry and livestock activity.

The GUI provides a friendly environment for the user to input and check scenario data and heuristic parameters (Fig. 4). A policy scenario is characterized by specific product prices and elasticity of supply and subsidies to each agro-forestry and livestock activity.

The GUI further enables the user to check DSS reports. It encompasses geographical reporting capabilities for the user to check the optimal spatial allocation of land uses (Fig. 5). Results are also presented in tabular format for the whole region (Fig. 6) or for each farm-type land unit (Fig. 7).

\subsection{Scenarios used}

Before 1992 the CAP allowed European farmers to benefit from high agricultural prices. This was possible through strong support price mechanisms, including guaranteed minimum prices, import tariffs, production quotas and limits to the imports on certain goods from outside the EU. Nevertheless surpluses became an increasing burden to the EU budget. This prompted the definition of other policies to support farmers' income.

The first CAP reform in 1992 addressed the budget problem, and it took into account the international negotiations in the Uruguay Round. Support mechanisms were introduced that had a substantial impact on the markets for cereals, oilseeds, protein crops and beef. The CAP reform further addressed territorial and environmental aspects by introducing, the agro-environmental measures (REG (CEE) 2078/92) and the forested land measures (REG (CEE) 2080/92). In the case of cereals, oilseeds and protein crops, minimum prices were reduced to approximate the international trade prices. Direct subsidies based on the area of these crops were introduced to compensate farmers. In addition, production quotas were reinforced and "set-aside" payments were introduced in an effort to prevent overproduction. To encourage the populations to stay in rural areas, the value of livestock premiums was increased substantially, namely for beef cattle.

In 1999 the European Union (EU) approved a new CAP reform, to reinforce agriculture competitiveness, multi-functionality and sustainability. The CAP became a rural development policy (REG (EU) 1257/99) with even stronger impact on forestry. In 2003 the PAC was again revised (REG (EU) 1782/2003 to 1788/2003). In spite of keeping 1999 reform objectives (e.g. competitiveness, multi-functionality and sustainability), it changed substantially the farmers' income support instruments. A single 


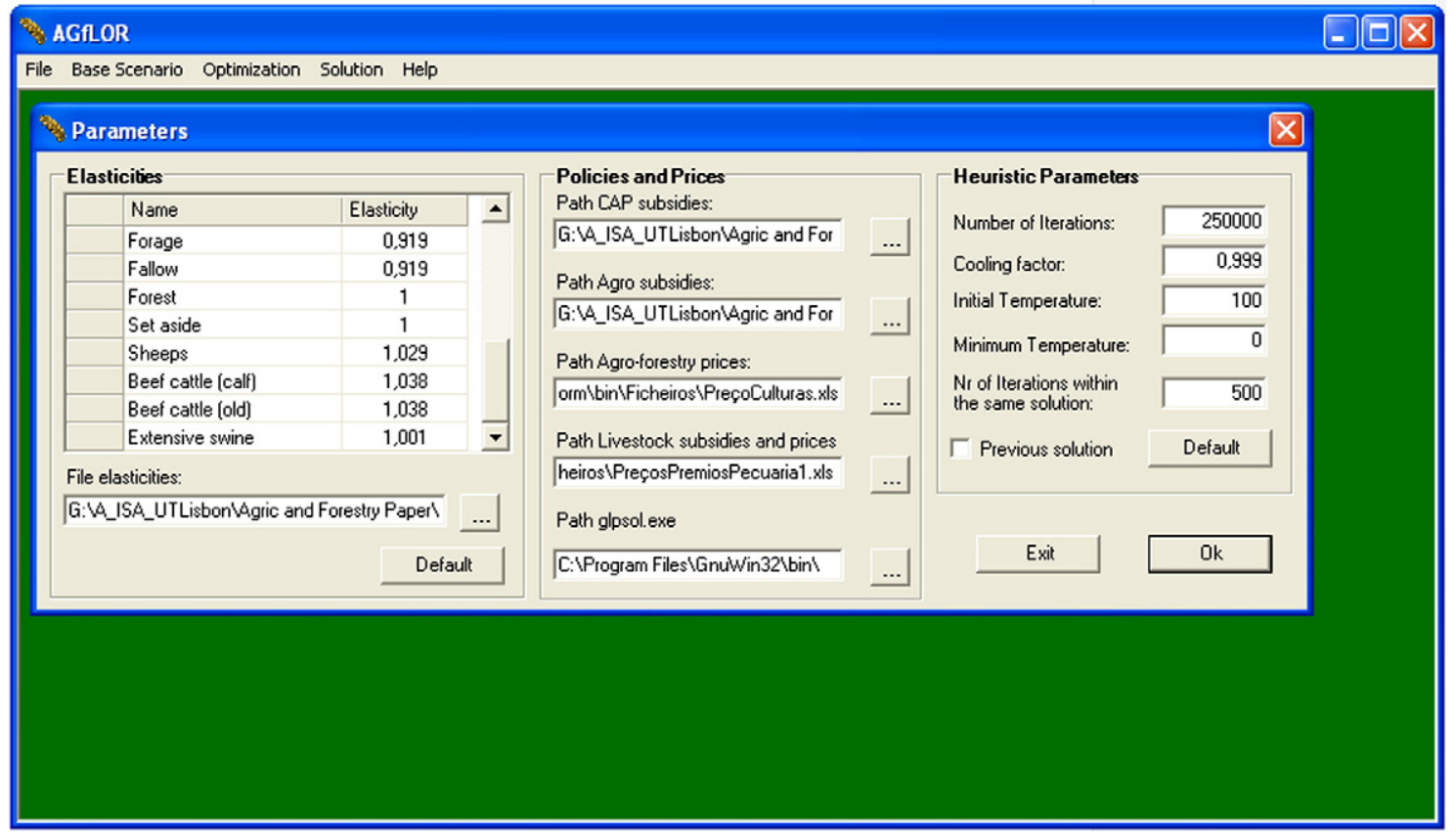

Fig. 4. AGfLOR introducing simulation parameters.

payment based on previous individual farmer rights replaced former subsidies (REG (EU) 1698/2005). The 2003 PAC reform also included a reduction on the subsidy levels through farm modulation and transfers of funds for rural development and for other economic activities in the rural areas. In 2005 there was considerable debate in the European Council of Ministers on the long-term EU budget known as the financial perspective for the period 2006-2013. There was pressure from some members to reduce or eliminate the CAP. These proposals were unsuccessful yet in 2012 a new budget will be discussed (Bakker et al., 2008). In this paper we address potential policy trends by defining a baseline scenario concerning the CAP reform of 1999 and two alternative scenarios for agricultural subsidies based on the production decoupling principle.

The first scenario (A1) is the baseline scenario that addresses the second CAP reform concerns (REG (EU) 1257/99). Subsidies are based on cereals, oilseeds and protein crops growing areas and on the number of livestock units. It reflects the agricultural subsidies levels in the Alentejo Region in 2005. It further encompasses national rural and agro-environmental policy goals (e.g. support to extensive agroforestry activities and organic farming).

The second scenario (B1) introduces the CAP reform of 2003, namely the direct payments by farm (REG (EU) 1698/2005). This scenario considers subsidy decoupling in the case of cereals, oilseeds and protein crops i.e. subsidies are no longer linked to the these crops' output. Livestock premiums and agro-environmental support are the only subsidies that have a direct relationship with production levels. Agro-environmental subsidies aim at expanding extensive agricultural activities, integrated protection in agricultural production, organic agriculture and extensive range management.

The third scenario (C1) assumes full subsidy decoupling. The impact on farmers' behaviour is similar to the impact of a full liberalization scenario with no agricultural subsidies. In this scenario no subsidies have a relationship with production levels and income just depends on the outputs of agricultural, forest and livestock activities. The financial support to farmers does not impact the agroforestry marginal production cost.

Based on scenario $\mathrm{C} 1$, a price sensitivity analysis was further conducted for some agricultural productions (i.e. cereals and oilseeds). Thus, in order to simulate current demand increase, a 50\% price hike was considered (scenario $\mathrm{C} 2$ ). To bound eventual farm income losses, scenario $C$ was re-simulated with a decrease on the price of cereals and oilseeds of 50\% (scenario C3). This assumption of price variation is greatly based on the international markets developments in 2008.

\section{Results}

It took $7 \mathrm{~min}$, on average, with an Intel $^{\circledR}$ Core $^{\mathrm{TM}}$ 2CPU 6400 processor operating at $2.13 \mathrm{GHz}$ with $3 \mathrm{~Gb}$ of RAM and running Ms Windows XP, for the proposed approach to determine the optimal combination of activities within all land units according to a policy scenario.

As an example of visualisation routine, the GIS module may be used to display a map where the presence of the tomato activity in farm-type land units is shown under the baseline scenario (A1) and the full decoupling (i.e. no subsidies have a relationship with production levels) subsidies scenario (C1) (Fig. 5). The system may also be used to display scenario results in tabular format for the whole region (Fig. 6). Moreover, the same structure is used to show the results for each one of the 31 farm-type units considered in Alentejo. In this case, the system presents the name, ID and the area of the farmtype land unit as well as the gross revenues and subsidies received (Fig. 7).

The proposed approach generated information that was instrumental to compare scenarios (Table 1). As expected, the reduction (scenario B1) or suppression (scenario C1) of subsidies leads to a decrease of agro-forestry activities. Nevertheless, the forest area increased slightly while the set-aside area increased substantially. The higher the reduction in subsidies the higher was the decrease in agroforestry areas and the higher the increase in set-aside areas. When subsidies were totally suppressed (scenario C1) or when only agroenvironmental subsidies were considered (scenario B1) the area devoted to agriculture decreased by up to $63 \%$. Cereals were the most impacted crop. The decrease in the area used for growing cereals reached up to 95 and 98\% under scenarios B1 and C1, respectively. On the other hand, set-aside areas showed a substantial increase of up to more than $440 \times 10^{3} \mathrm{ha}$. In this case, the increase of forest area, up to $2.5 \%$, represented an expansion of up to $4.5 \times 10^{3}$ ha (Table 1 ). As most of the cereal is linked to the "Montado" a decrease or suppression of 


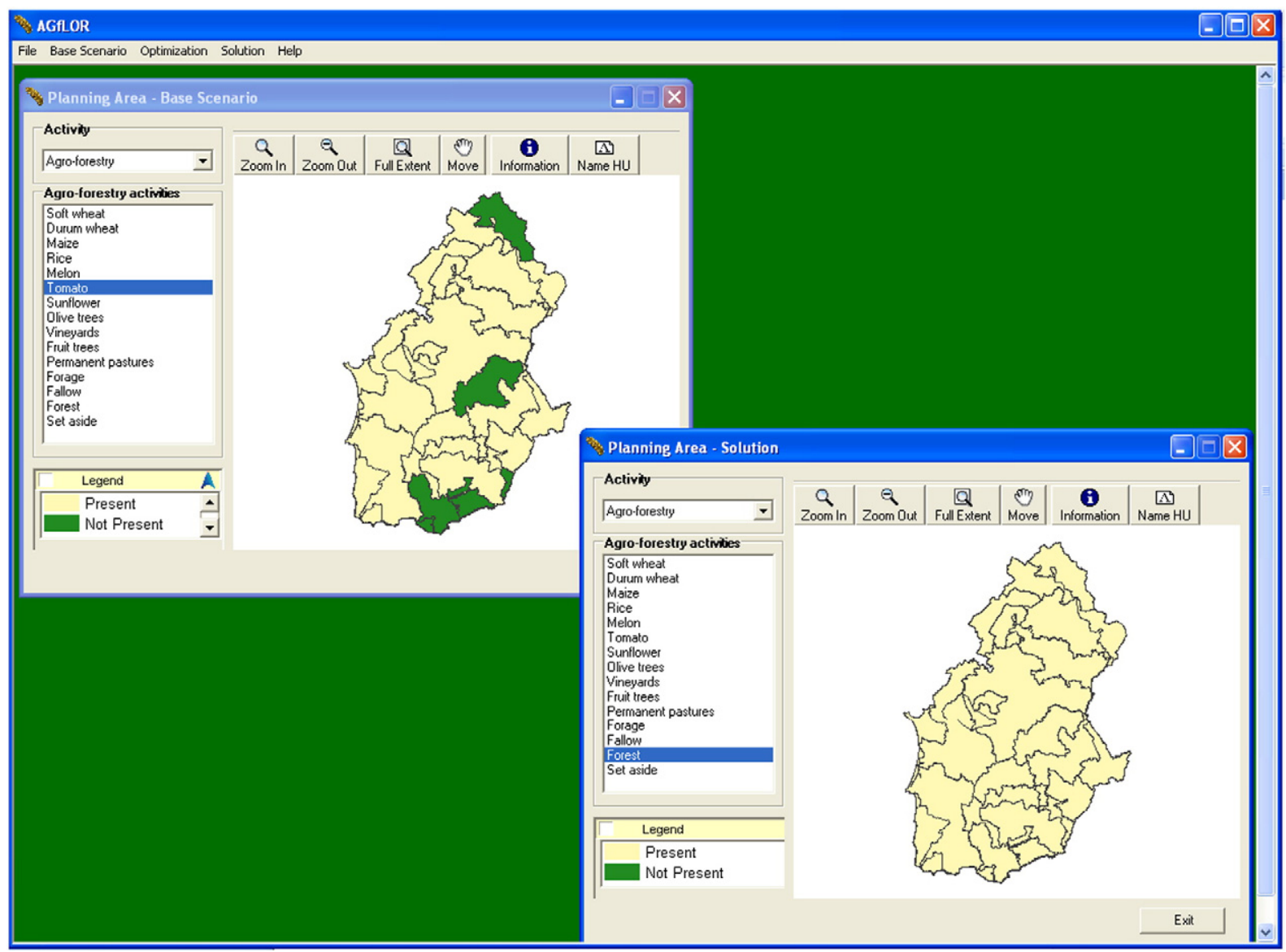

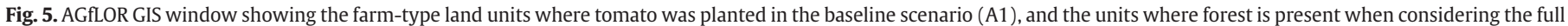
decoupling subsidy scenario (C1).

subsidies represents a change in the crops grown under tree cover (e.g. increase of set-aside). However, the area of the tree cover of the Montado, (i.e. Quercus ilex spp. rotundifolia and Quercus suber) does not change because it is forbidden by Portuguese and European law to harvest both oaks.

For the situation where no subsidies and an increase in the cereal prices by $50 \%$ are considered (scenario C2), the area with maize is substantially expanded (209\%) whereas the areas with common wheat and durum wheat are reduced (34\% and 97\%). The total cultivated areas also decreased (51\%). However, the decrease in cultivated area was smaller than in scenario C1 where prices remained constant, which means that the increase in prices help to compensate the impact of the suppression of subsidies. In these conditions the forest area with no agriculture activity under the canopy cover was slightly increased (3\%). This represented an increase in the forest area of almost $5 \times 10^{3}$ ha. Set-aside areas were substantially increased ( $519 \%$ and $410 \times 10^{3}$ ha).

If the price of cereals is reduced by $50 \%$ (scenario C 3 ), the cereals' area is reduced by more than $90 \%$. The cultivated area was reduced by $63.3 \%$ to $350 \times 10^{3}$ ha. In addition, set-aside area increased by $455 \times 10^{3}$ ha. In this case the forest area with no agriculture activity under the canopy cover remained almost constant (increase of $1 \%$ ). "Montado" was greatly impacted as the area devoted to crops that are grown under oak species is reduced by over $90 \%$. However, the area occupied by pastures was relatively less impacted than other land uses. Whereas pastures occupied $61 \%$ of the area (excluding fallow, setaside and forest areas) in the baseline scenario, this percentage raised to $78 \%$ of the area in the $\mathrm{C} 3$ scenario. Thus, the relative importance of the pastures on the agro-forestry system was increased. This means that crops are becoming less important in this system while the importance of pastures is becoming relatively more important.

When subsidies are reduced in scenarios B1 and C1, the number of livestock units also decreases. The scenario without subsidies leads to the highest decrease (16\%). In this scenario beef cattle and sheep are drastically reduced by $22 \%$ and $11 \%$, respectively. On the other hand, extensive swine would increase $2 \%$. Yet if the agro-environmental subsidies are maintained (scenario B1) this increase would approximate $4 \%$. This positive trend is not found for beef and sheep cattle.

Policy impacts on economic results are consistent with the impacts on cultivated areas. The reduction in subsidies in scenarios B1 or C1 leads to a decrease in crop output levels and corresponding gross revenues. The highest reduction in gross revenues was found in scenario C1 (81\%). In this scenario the output values decrease by $52 \%$. Under scenario B1 these crop output levels and gross revenues decreased $68 \%$ and $26 \%$, respectively.

\section{Discussion}

The current implementation of the proposed approach was computationally effective. The modular structure allows for extension and updating of the different modules and the database. Coding improvements may further lead to better computational performances. Nevertheless, the solution quality and speed by simulated annealing are very sensitive to parameter settings. Furthermore, parameters are problem-specific and require considerable user study to understand their behaviour in arriving at a solution (e.g. Reeves, 1993; Pham and Karaboga, 2000; Falcão and Borges, 2002). Some expertise is needed so that the tool may generate insight and may 


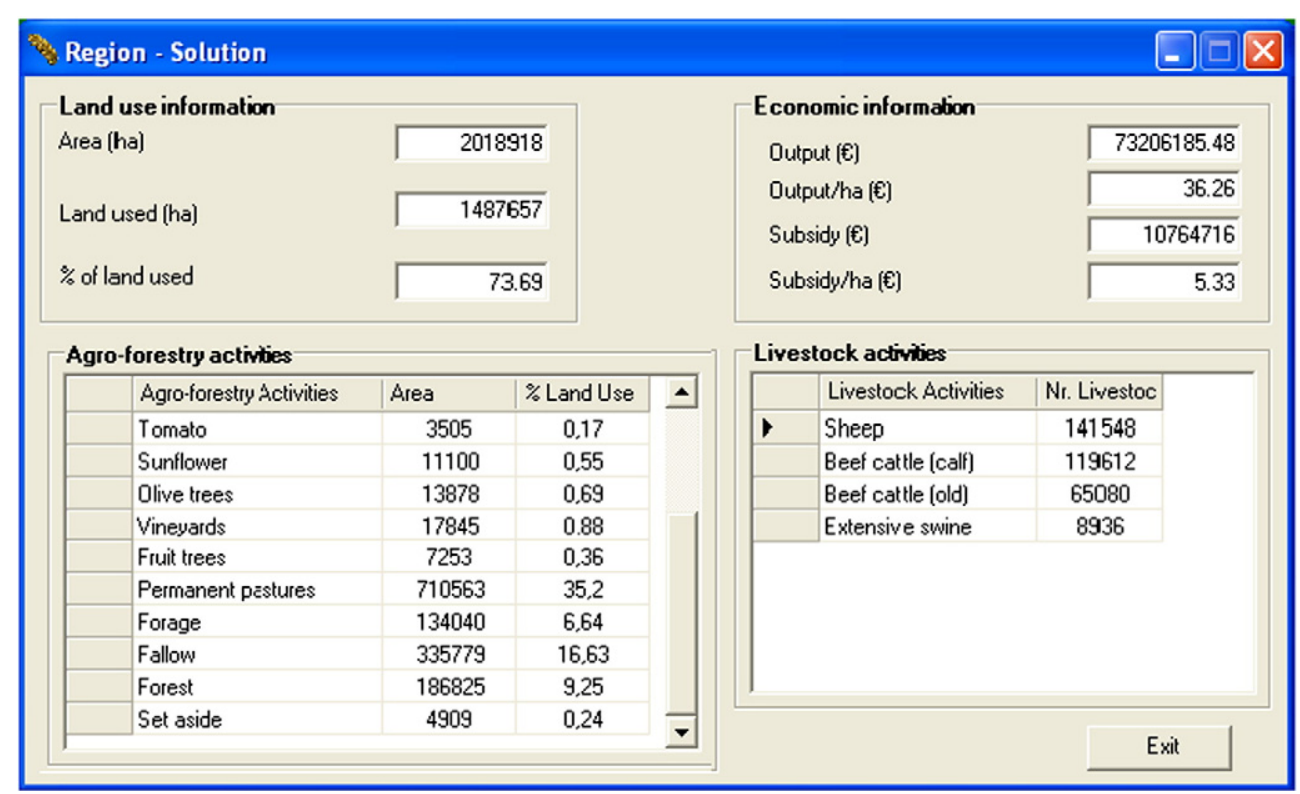

Fig. 6. AGfLOR table showing the aggregated results for the whole region using the full decoupling subsidy scenario (C1).

help interpret the impact of policies and prices on regional land use patterns, namely on forestry and agro-forestry activities.

The PMP approach that was integrated in the DSS employs both programming constraints and positive inferences from the base year land use allocation. The approach potential for applied analysis is evident as it automates model calibration based on sound empirical data. However the PMP approach assumes that the observed land allocation in the base year is optimal. Further, it does not allow for the inclusion in the calibration process of activities that have not been observed in the base year (Howitt, 1995; Paris and Howitt, 1998). This may limit the prescribing behaviour capacity of the proposed approach especially in a context of great technical and economic changes. Yet it provides smooth results close to current economic behaviour in rural zones (Howitt, 1995; Baskaqui et al., 2001; Fragoso et al., 2008).

Scenario analysis by the proposed approach was coherent with findings of other authors (e.g. Pinto-Correia and Mascarenhas, 1999). The suppression of subsidies (C1) had a depressing impact on economic results even when cereal prices increased (C2). This shows that subsidies to agriculture-forestry activities have a substantial impact on farm income and on production decisions. Reduction of subsidies leads to progressive abandonment and setting-aside of agricultural land. The importance of pastures in the Montado system was thus increased. Pinto-Correia and Mascarenhas (1999) pointed out that in the "Montado", cultivation is becoming less important in the system rotation, whereas livestock production is becoming more relevant, the ground cover being used mostly as pasture.

\section{Conclusion}

In Portugal there was considerable experience of developing DSS to enhance the efficiency and the effectiveness of forest management planning (e.g. Borges et al., 2003; Ribeiro et al., 2004; Falcão and Borges, 2005; Ribeiro et al., 2005, Falcão et al., 2006; Borges et al., 2008a,b). Yet these DSS did not include the Positive Mathematical Programming (PMP) approach. This paper demonstrated that the proposed model base approach in the framework of a DSS is able to anticipate the impacts of changes in CAP and/or in prices on land use in rural areas (including forest land).

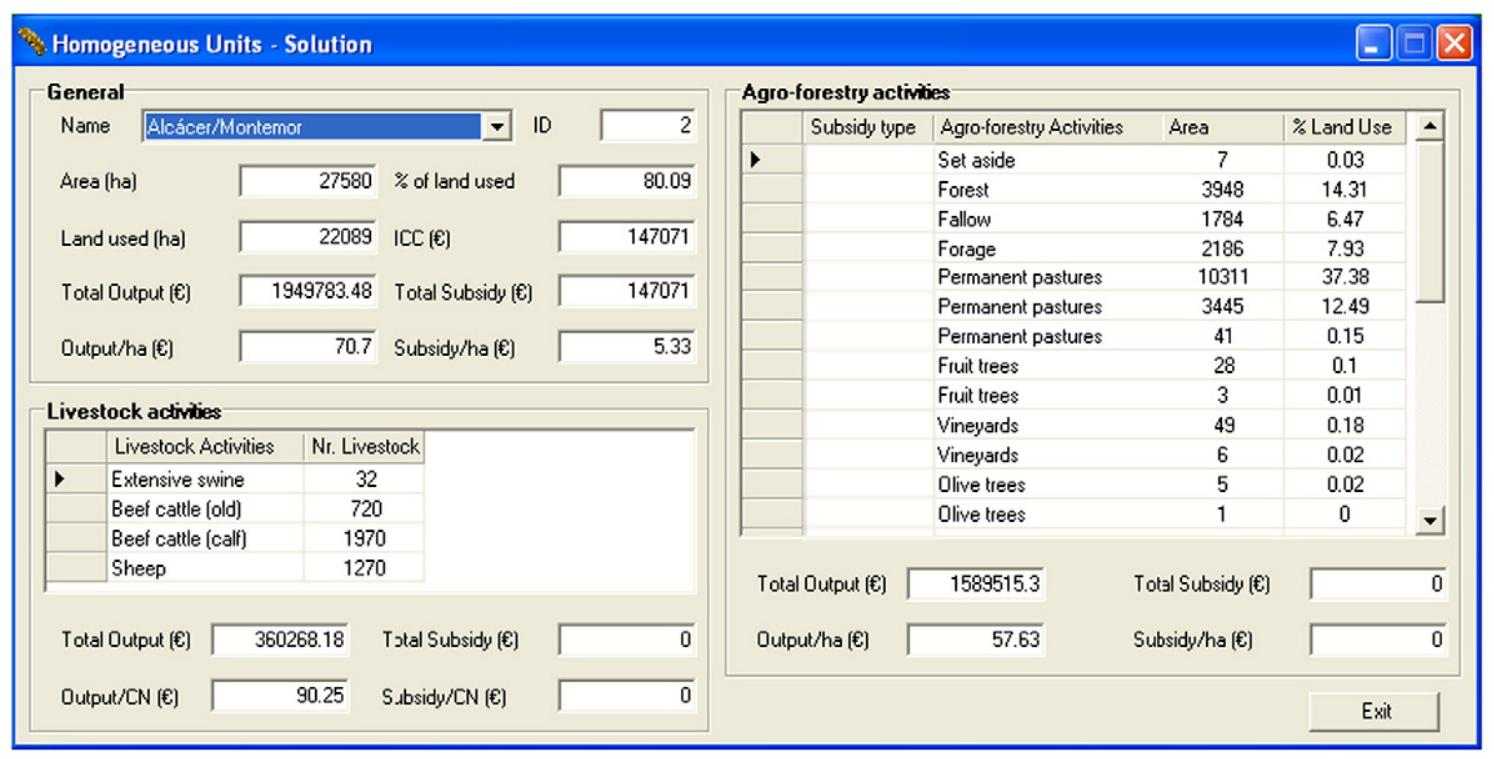

Fig. 7. AGfLOR table showing the results disaggregated for one of the 31 farm-type land units in the region (C1 scenario). 
Table 1

Agro-forestry and livestock activity levels and economic results for Alentejo Region by each simulation scenario.

Source: Model DSS results.

\begin{tabular}{|c|c|c|c|c|c|c|c|c|c|}
\hline \multirow[t]{3}{*}{ Agricultural activities } & \multicolumn{9}{|l|}{ Scenarios } \\
\hline & \multirow{2}{*}{$\begin{array}{l}\mathrm{A} 1 \\
\text { ha }\end{array}$} & \multicolumn{2}{|c|}{ B1 } & \multicolumn{2}{|c|}{$\mathrm{C} 1$} & \multicolumn{2}{|c|}{$\mathrm{C} 2$} & \multicolumn{2}{|c|}{$\mathrm{C} 3$} \\
\hline & & ha & $\Delta \%$ & ha & $\Delta \%$ & ha & $\Delta \%$ & ha & $\Delta \%$ \\
\hline Common wheat & 26.982 & 2.266 & -91.6 & 3.211 & -88.1 & 17.754 & -34.2 & 2.401 & -91.1 \\
\hline Durum wheat & 144.772 & 8.107 & -94.4 & 7.962 & -94.5 & 4.633 & -96.8 & 6.225 & -95.7 \\
\hline Maize & 20.419 & 1.184 & -94.2 & 2.369 & $-88,4$ & 63.115 & 209.1 & 898 & -95.6 \\
\hline Rice & 10.318 & 268 & -97.4 & 371 & -96.4 & 382 & -96.3 & 495 & -95.2 \\
\hline Melon & 2.563 & 2.691 & 5.0 & 2.484 & -3.1 & 2.650 & 3.4 & 2.740 & 6.9 \\
\hline Tomato & 4.274 & 3.394 & -20.6 & 3.351 & -21.6 & 3.227 & -24.5 & 3.466 & -18.9 \\
\hline Sunflower & 32.001 & 14.464 & -54.8 & 10.432 & -67.4 & 10.656 & -66.7 & 10.848 & -66.1 \\
\hline Olive tree & 131.775 & 15.945 & -87.9 & 14.759 & -88.8 & 14.627 & -88.9 & 16.077 & -87.8 \\
\hline Vineyards & 18.194 & 18.431 & 1.3 & 17.430 & -4.2 & 17.539 & -3.6 & 17.284 & -5.0 \\
\hline Fruit trees & 7.392 & 7.362 & -0.4 & 7.481 & 1.2 & 7.340 & -0.7 & 7.281 & -1.5 \\
\hline Forage & 155.355 & 139.043 & -10.5 & 135.470 & -12.8 & 130.654 & -15.9 & 135.780 & -12.6 \\
\hline Fallow & 320.774 & 336.171 & 4.8 & 341.945 & 6.6 & 346.436 & 8.0 & 337.454 & 5.2 \\
\hline Permanent pastures & 881.658 & 765.279 & -13.2 & 748.528 & -15.1 & 722.078 & -18.1 & 759.108 & -13.9 \\
\hline Total cultivated area ${ }^{a}$ & 554.045 & 213.155 & -61.5 & 205.320 & -62.9 & 272.577 & -50.8 & 203.495 & -63.3 \\
\hline Forests $^{\mathrm{b}}$ & 183.411 & 184.511 & 0.6 & 187.813 & 2.4 & 187.996 & 2.5 & 185.062 & 0.9 \\
\hline Set-aside & 79.030 & 519.800 & 557.7 & 535.313 & 577.3 & 489.831 & 519 & 533.798 & 575.4 \\
\hline Total area occupied ${ }^{\mathrm{C}}$ & 2.018 .918 & 2.018 .918 & - & 2.018 .918 & - & 2.018 .918 & - & 2.018 .918 & - \\
\hline Livestock activities & Unit head & Unit head & $\Delta \%$ & Unit head & $\Delta \%$ & Unit head & $\Delta \%$ & Unit head & $\Delta \%$ \\
\hline Total livestock unit heads & 401.092 & 345.030 & -14 & 334.898 & -16 & 336.284 & -19 & 328.606 & -16 \\
\hline Sheep & 159.424 & 141.887 & -11 & 141.887 & -11 & 140.293 & -12 & 145.076 & -9 \\
\hline Breeding cattle & 152.550 & 128.142 & -16 & 118.989 & -22 & 126.617 & -17 & 115.938 & -24 \\
\hline Beef cattle & 80.373 & 65.906 & -18 & 65.102 & -19 & 60.280 & -25 & 58.672 & -27 \\
\hline Extensive swine & 8.745 & 9.095 & 4 & 8.920 & 2 & 9.095 & 4 & 8.920 & 2 \\
\hline Economic results & $€ /$ ha & $€ /$ ha & $\Delta \%$ & $€ /$ ha & $\Delta \%$ & $€ /$ ha & $\Delta \%$ & $€ /$ ha & $\Delta \%$ \\
\hline Income & 76 & 56 & -26 & 37 & -52 & 70 & -8 & 37 & -51 \\
\hline Production subsidies & 138 & 12 & -91 & 6 & -96 & 6 & -96 & 6 & -96 \\
\hline Gross revenue & 215 & 69 & -68 & 41 & -81 & 75 & -65 & 43 & -80 \\
\hline
\end{tabular}

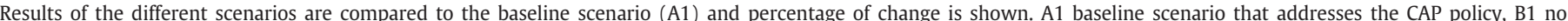

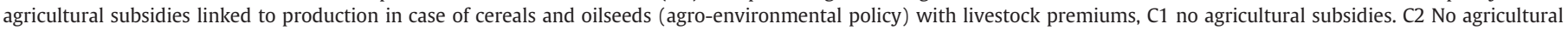
subsidies and a 50\% price hike for cereals and oilseeds. C3 indicates a 50\% price decrease for cereals and oilseeds.

a Area that does not include land in set-aside, fallow, pastures and forests.

b Forest refers to forest with no or little agricultural activity under canopy cover.

c Area that has a specific agro-forestry use.

This paper showed that such an integrated DSS model may be used for assessing policy impacts on agriculture and forestry. For that purpose, it takes advantage of the integrated functionality of a linear programming model to estimate the Positive Mathematical Programming production cost function coefficients of current agricultural and forest activities, of a heuristic - simulated annealing - to generate solutions for each policy scenario, of a relational database that stores agro-forestry technical and economic data and of a geographic information system that stores topological data of regional land units.

This model base approach to anticipate the impact of changes in policy and/or prices on land use might be used by policy makers in order to decide which policies are better suited for specific objectives. In this study case, the approach was specifically used to determine the optimal combination of activities within all land units according to a set of price and policy scenarios. The proposed approach provided valuable information leading us to conclude that subsidies that are linked to agricultural activities have a substantial impact on farm income and on production decisions. Thus, reduction in subsidies leads to a progressive abandonment and setting-aside of agricultural land and to the decrease of the total output value from the agro-forestry activities. Under these conditions the relative importance of pastures within agro-forestry systems increased considerably while forest land increased slightly.

\section{References}

Bach, M., Lutz Breuer, L., Frede, H-G., 2008. The Integrated Tool for Economic and Ecological Modeling (ITE2M): assessment of trade-offs in landscape services. Impact Assessment of Land Use Changes Conference Proceedings. Humboldt University, Unter den Linden, Berlin, Germany.
Bakker, M., Boitier, B., Fougeyrollas, A., Helming, J., Jansson, T., Verkerk, P.J., 2008. Assessing policy impacts on European land-use change through cross-sectoral modeling. Impact Assessment of Land Use Changes Conference Proceedings. Humboldt University, Unter den Linden, Berlin, Germany.

Baskaqui, A., Butault, J., Rousselle, J., 2001. Positive mathematical programming and agricultural supply within EU under Agenda 2000. EAAE Proc. 65th European Association of Agricultural Economists, Bonn, Vauk Verlag Kiel, 2000, p. 200.

Borges, J.G., Hoganson, H.M., Falcão, A.O., 2002. Heuristics in multi-objective forest management. In: Pukkala, T. (Ed.), Multi-objective Forest Planning. : Managing Forest Ecosystems, vol. 5. Kluwer Academic Publishers, pp. 119-152.

Borges, J.G., Falcão, A., Miragaia, C., Marques, P., Marques, M., 2003. A decision support system for forest resources management in Portugal. In: Arthaud, G.J., Barrett, T.M. (Eds.), System Analysis in Forest Resources. : Managing Forest Ecosystems, vol. 7. Kluwer Academic Publishers, pp. 155-164.

Borges, P., Marques, S., Borges, J.G., Tomé, M., 2008a. Scenario analysis applied to cork and holm oak forest ecosystems in Southern Portugal. In: Palahi, M., Birot, Y., Bravo, F., Gorris, E. (Eds.), Modelling, Valuing and Managing Mediterranean Forest Ecosystem for Non-timber Goods and Services, EFI Proceedings, vol. 57, pp. $49-56$.

Borges, P., Marques, S., Marto, M., Borges, J.G., 2008b. O Sistema de Apoio à Decisão em Análise de Cenários de Montados de Sobro e Azinho no Alentejo MfLOR, Documento Técnico no. 02/08, FORCHANGE. Departamento de Engenha ria Florestal, Instituto Superior de Agronomia, Lisboa.

Cypris, C., 2000. Positiv Mathematische Programmierung (PMP) im Agrarsektormodells RAUMIS. University of Bonn, Dissertation.

Falcão, A.O., Borges, J.G., 2002. Combining random and systematic search heuristic procedures for solving spatially constrained forest management scheduling problems. Forest Science $48,608-621$.

Falcão, A., Borges, J.G., 2005. Designing decision support tools for Mediterranean forest ecosystems management: a case study in Portugal. Annals of Forest Science 62, 751-760.

Falcão, A.O., Próspero dos Santos, M., Borges, J.G., 2006. A real-time visualization tool for forest ecosystem management decision support. Computer and Electronics in Agriculture 53, 3-12.

Fragoso, R., Carvalho, M.L., Henriques, P.D., 2008. Positive Mathematical Programming: a Comparison of Different Specification Rules: 12th Congress of the European Association of Agricultural Economists - EAAE. 
Gohn, A., Chantreuil, F., 1999. La programmation mathématique positive dans les modèles d'exploitation agricole. Principes et l'importance du calibrage. Cahiers d'Economie et de Sociologie Rurales 52, 59-79.

Graindorge, C., Henry de Frahan, B., Howitt, R., 2001. Analysing the Effects of Agenda 2000 Using a CES Calibrated Model of Belgian Agriculture. In: Heckelei, T., Witzke, H.P., Henrichsmeyer, W. (Eds.), Agricultural Sector Modelling and Policy Information Systems. Vauk Verlag, Kiel.

Helming, J.F.M., Peeters, L., Veendendaal, P.J.J., 2001. Assessing the consequences of environmental policy scenarios in Flemish agriculture. In: Heckelei, T., Witzke, H.P., Henrichsmeyer, W. (Eds.), Agricultural Sector Modelling and Policy Information Systems. Vauk Verlag, Kiel.

Howitt, R.E., 1995. Positive mathematical programming. 2American Journal of Agricultural Economics 77, 329-342.

INE, 1999. Instituto Nacial de Estatistica.

Mccarl, B., Spreen, T., 1980. Price endogenous mathematical programming as a tool for sector analysis. American Journal of Agricultural Economics 87-102.

Paris, Q., Howitt, R.E., 1998. An analysis of ill-posed production problems using maximum entropy. American Journal of Agricultural Economics 80 (1), 124-138.

Pham, D.T., Karaboga, D., 2000. Intelligent Optimisation Techniques: Genetic Algorithms, Tabu Search, Simulated Annealing and Neural Networks. Springer-Verlag, London. 302p.

Pinto-Correia, T., Mascarenhas, J., 1999. Contribution to the extensification/intensification debate: new trends in the Portuguese Montado. Landscape and Urban Planning 46, 125-131.

Reeves, C.R., 1993. Modern Heuristic Techniques for Combinatorial Problems. John Wiley, New York. 320p.
Reynolds, K.M., Borges, J.G., Vacik, H., Lexer, M.J., 2005. Information and communication technology in forest management and conservation. In: Hetemaki, L., Nilsson, S. (Eds.), Information Technology and the Forest Sector. : IUFRO World Series, vol. 18 International Union of Forest Research Organizations, Vienna, Austria, pp. 150-171.

Reynolds, K.M., Twery, M., Lexer, M.J., Vacik, H., Ray, D., Shao, G., Borges, J.G., 2008 Decision support systems in natural resource management. In: Burstein, F., Holsapple, C. (Eds.), Handbook on Decision Support Systems. : International Handbooks on Information Systems Series, 2. Springer, pp. 499-534.

Ribeiro, R.P., Borges, J.G., Oliveira, V., 2004. A framework for data quality for Mediterranean sustainable ecosystem management. Annals of Forest Science 61, 557-568.

Ribeiro, R.P., Borges, J.G., Pereira, C.M., Sousa, P.M., Lé, J.P., 2005. Designing an Integrated Forest Planning System for the forest industry: an application in Portugal. In: Bevers, M., Barrett, T.M. (Eds.), Systems Analysis in Forest Resources. : Proceedings of the 2003 Symposium, October 7-9, 2003, Stevenson, WA, USA. Gen. Tech. Rep. PNW-GTR-656. U.S. Department of Agriculture, Forest Service, Pacific Northwest Research Station, Portland, OR, pp. 89-96.

Somarriba, E., 1992. Revisiting the past - an essay on agroforestry definition. Agroforestry Systems. 19, 233-240.

van Delden, H., Luja, P., Paracchini, M.L., Stuczynski, T., Ciaian, P., 2008. The LUMOCAP PSS, impact assessment of agricultural policies in an integrative context. Impact Assessment of Land Use Changes Conference Proceedings. Humboldt University, Unter den Linden, Berlin, Germany.

Zahedi, F., Song, J., Jarupathirun, S., 2008. Web-based decision support. In: Burstein, F. Holsapple, C.W. (Eds.), Handbook on Decision Support Systems 1. Springer Berlin, Heidelberg, pp. 315-338. 